\title{
Aortic Dissections in Marfan Disease During Pregnancy: Review Article
}

\author{
Jesse Cottrell $^{1}$, John Calhoun ${ }^{2}$, Jamie Szczepanski², Joel Corvera ${ }^{3}$, Lawrence Creswell ${ }^{4}$, \\ Brian Kogon ${ }^{2}$, Nahidh Hasaniya ${ }^{5}$, and Hannah Copeland ${ }^{2}$ \\ ${ }^{1}$ Marshall University \\ ${ }^{2}$ University of Mississippi Medical Center \\ ${ }^{3}$ Indiana University School of Medicine \\ ${ }^{4}$ University of Mississippi \\ ${ }^{5}$ Loma Linda University Medical Center
}

June 11, 2020

\begin{abstract}
We want to thank Dr. Raveenthiran and Dr. Harky for their interest in our paper and in the topic of Marfans in the setting of pregnancy. Certainly, the reduction of adverse outcomes would be improved with early knowledge of Marfans syndrome in the mother which would aid in preparation and clinical consideration during the perioperative period, and, prior to pregnancy.
\end{abstract}

\section{Response Letter to the Editor:}

Title: Aortic Dissections in Marfan Disease During Pregnancy: Review Article

Short Title: Aortic Dissections in Marfan Disease During Pregnancy

Keywords: "Aorta and Great vessels", "Marfan", "Pregnancy", "Aortic dissection"

Authors: Jesse Cottrell, MD (Marshall University); John T. Calhoun, MD (University of Mississippi Medical Center); Jamie Szczepanski, MD (Marshall University); Joel Corvera, MD (Indiana University); Lawrence L. Creswell (University of Mississippi Medical Center), MD; Brian Kogon (University of Mississippi Medical Center), MD; Nahidh Hasaniya, MD (Loma Linda University Medical Center); Hannah Copeland, MD (University of Mississippi Medical Center)

Institutional affiliations: University of Mississippi Medical Center

Corresponding author information: Hannah Copeland, MD. Hannahcopeland411@gmail.com

Dear Editor,

We offer our thanks to Dr. Raveenthiran and Dr. Harky for their interest in our paper and in the topic of Marfans in the setting of pregnancy. Certainly the reduction of adverse outcomes would be improved with early knowledge of MFS in the mother which would aid in preparation and clinical consideration during the perioperative period and, of course, in general. Each of the cases presented in our paper had established diagnoses and lends weight to this suggestion. The work by Meijboom et al. was indeed encouraging as we constructed our recommendations for evaluating the risk to a potential mother. The conclusion of that paper, as we discussed in our review, was that pregnancy is likely safe up to an aortic root diameter of $45 \mathrm{~mm}^{2}$, and speaks to the value of early detection of disease [2]. The recently released work by Dr. Harky identifies the Marfans population in England and Wales undergoing planned and non-planned Aortic root 
surgery, and assesses outcomes. While it does not specifically address Marfans in pregnancy, it reported satisfactory outcomes for 306 Marfans patients, 100 of which were female, and suggests, as our paper does, that Aortic root surgery in this cohort remains an evolving but achievable challenge [1]. The call for an international registry to assess the work up and outcomes of this patient population is a worthy one which we would be happy to participate in.

References:

1. Harky A, Shaw M, Bashir M. Thoracic Aortic Aneurysm Surgery in Marfan Patients: a Perspective from the UK. Braz J Cardiovasc Surg. 2020 May 1;35(1):58-64. doi: 10.21470/1678-9741-2019-0214.

2. Meijboom L, Vos F, Timmermans J, Boers G, Zwinderman A, Mulder B. Pregnancy and aortic root growth in the Marfan syndrome: a prospective study. Eur Heart $J$. 2005;26(9):914-920 